\title{
A Comparison of Manual and Automatic Moth Sampling Methods (Lepidoptera: Arctiidae, Geometridae) in a Rain Forest in Costa Rica
}

\author{
GUNNAR BREHM ${ }^{1,2}$ AND JAN C. AXMACHER ${ }^{3}$
}

\begin{abstract}
Environ. Entomol. 35(3): 757-764 (2006)
ABSTRACT Sampling with UV fluorescent light tubes is a commonly used technique both in applied and basic insect studies. Our study compares the performance of two such methods: manual sampling (light towers) and automatic sampling (funnel light traps). The abundance, diversity, and body size of moths representing two species-rich families (Lepidoptera: Arctiidae, Geometridae) were analyzed in a lowland rain forest in Costa Rica (La Selva Biological Station, $10.4^{\circ} \mathrm{N}, 84.0^{\circ} \mathrm{W}$ ) during 2003 and 2004. Light towers were equipped with two 15-W UV fluorescent tubes and were operated for $3 \mathrm{~h}$ in 16 nights. Traps equipped with single 8-W fluorescent tubes were run throughout 20 nights in the understory of the forest. In addition, parallel trap sampling was carried out in the canopy. A total of 1,238 arctiid moths representing 162 species and 1,769 geometrid moths representing 196 species were collected. In Geometridae, tower samples were significantly larger than trap samples. Towers also attracted a higher overall number of species. Very small geometrids (particularly of the subfamily Sterrhinae) were under-represented in trap samples, suggesting that this method is biased toward larger species. In arctiid moths, there were no significant differences in either the sample sizes, the number of species or in the size of the individuals sampled. Diversity calculated as Fisher's $\alpha$ was similar for towers and understory traps in both families. A major component of diversity was added with canopy trap samples for arctiid moths, but not for geometrid moths. In conclusion, ground-based tower sampling proved to be the most suitable method for geometrid moths, and trap sampling including both understory and canopy for arctiid moths. For full moth species inventories, a combination of both approaches is recommended.
\end{abstract}

KEY WORDS arctiid moths, Costa Rica, geometrid moths, insects, light traps

Many nocturnal Lepidoptera species are easily attracted to artificial light sources (Canaday 1987, Muirhead-Thomson 1991). The underlying physiological and behavioral mechanisms of this attraction as well as the influence of weather, moonlight, and wind on light trap catches are still not fully understood (Bowden 1982, McGeachie 1989, Holyoak et al. 1997). However, no other trapping method has proved so consistently successful in capturing large numbers of such a great variety of moth species (Muirhead-Thomson 1991). Light traps have been used for monitoring in applied and basic entomology for $>50 \mathrm{yr}$ (Leinonen et al. 1998), and lepidopterists have employed a variety of different light sources, including gas lamps, mercury vapor lamps, and fluorescent tubes. Manual sampling has been carried out using these types of lamps, usually combined with sheets or other reflective material. In addition, automatic traps have been constructed where insects attracted to light drop into a sampling or

\footnotetext{
${ }^{1}$ Department of Animal Ecology I, Universitätsstraße 30, 95447 Bayreuth, Germany.

${ }^{2}$ Corresponding author: Institut für Spezielle Zoologie und Evolutionsbiologie mit Phyletischem Museum, Erbertstra $\beta$ e 1, 07743 Jena, Germany (e-mail: Gunnar Brehm@yahoo.com).

${ }^{3}$ Department of Geography, University College London, Pearson Building, Gower Street, London WC1E 6BT, UK.
}

killing device. These greatly facilitated long-term and all-night sampling. This diversity of approaches, however, causes problems with regard to the comparability of samples obtained by various light sources and trap designs. Although it would be desirable to use one standard method for quantitative moth sampling globally, a certain "diversity" of sampling methods seems to be inevitable. For example, traps must be adjusted to certain environments such as regions with background illumination (Leinonen et al. 1998) or very rainy areas.

One way to overcome the problem of the lack of standardization is to compare the different methods and to cross-calibrate the existing types of standard techniques as suggested by Holloway et al. (2001). An improved knowledge of the strengths and biases of certain methods will furthermore help in selecting the most appropriate method for future studies and could ease the interpretation of existing and future results.

This paper aims to compare two UV fluorescent light sampling techniques. A major advantage of using UV tubes in fieldwork is that the equipment is relatively light and hence can be stowed in a backpack and carried to remote areas. Other commonly used equipment such as traps operated with mercuray vapor bulbs (e.g., Robinson traps) is heavier and often less 


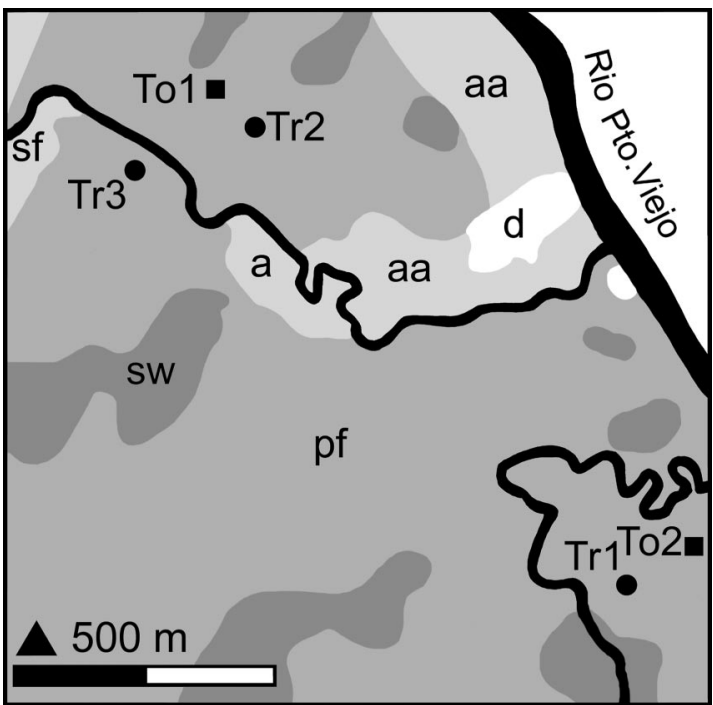

Fig. 1. Map of the study area at La Selva Biological Station, province Heredia, Costa Rica $\left(10.4^{\circ} \mathrm{N}, 84.0^{\circ} \mathrm{W}\right)$. Tol, To2, tower sites 1 and 2; Tr1-Tr3, automatic trap sites 1-3; a, arboretum (light gray); aa, abandoned agroforestry (light gray); d, developed area (white); pf, primary old growth forest (medium gray); sf, secondary forest (light gray); sw, forested swamp or open swamp (dark gray). Black lines, rivers. Information simplified from a GIS map by the Organization for Tropical Studies.

suited to studies that require sampling at many distant sites within short time periods.

In this study, the performance of a manual sampling technique using a light tower was tested against a type of automatic funnel trap. Light towers closely resemble the commonly used combination of UV tubes or bulbs with sheets, but the light is spread more equally in all directions. They have recently been used in a number of quantitative moth diversity studies in Asia, Africa, and South America (Schulze et al. 2001, Brehm et al. 2003, Brehn 2006, Axmacher et al. 2004, Hilt and Fiedler 2005). The automatic traps used in this study have frequently been used in the Arthropods of $\mathrm{La}$ Selva (ALAS) project (J. T. Longino, personal communication), as well as in studies in Europe and Australia (B. Skule, personal communication). Recently, Axmacher and Fiedler (2004) concluded that manual sampling of geometrid moths with a light tower had proved superior to automatic light traps using identical 15-W UV fluorescent light tubes in a montane rain forest in Tanzania. According to their results, we examined the following hypotheses: (1) manual sampling is more effective in terms of the numbers of individuals sampled; (2) overall moth diversity is higher in the manual collections; and (3) automatic samples represent only a portion of manual samples with a bias toward relatively large species.

The field work for this study was conducted in a mature neotropical lowland rain forest using two moth families as model taxa (Geometridae, Arctiidae). Light towers and automatic traps were operated in close
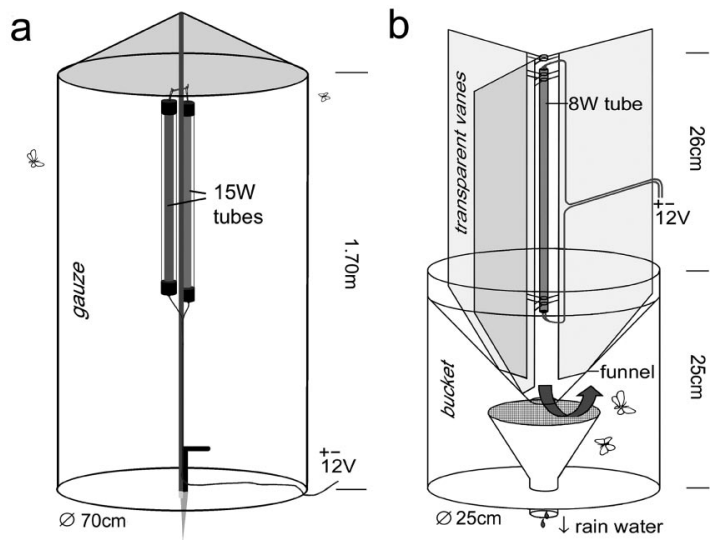

Fig. 2. Light tower (a) and automatic trap (b) used in this study. (a) The two 15-W UV fluorescent light tubes operate in the center of the gauze cylinder. Moths landing on the surface can easily be collected manually with a killing jar. (b) Moths were attracted to automatic traps using an 8-W UV fluorescent light tube. They glided down the transparent vanes through the funnel into a black bucket where a killing agent $(\mathrm{KCN})$ was applied. Rain water was allowed to run off through a second funnel. Egg carton was put into the trap to avoid damage to the insects. Traps were operated in parallel in the understory and in the forest canopy while the light tower was only used in the understory. All light tubes were run by a $12-\mathrm{V}$ lead battery. Note the different scales in a and $\mathrm{b}$.

proximity in the forest understory. Because traps were also operated in the canopy, respective samples were included in the analysis where appropriate. As the focus of this paper is sampling methodology, the ecological interpretation of the vertical stratification and body size patterns of moth ensembles has been published elsewhere (Brehm 2006).

\section{Materials and Methods}

Study Area. The study area is situated in a lowland rain forest on the base of the Caribbean slopes of the Cordillera Central at the La Selva Biological Station, Heredia province, in Costa Rica $\left(10.4^{\circ} \mathrm{N}, 84.0^{\circ} \mathrm{W}\right)$. According to Sanford et al. (1994), the annual precipitation in the study area is $\approx 4,000 \mathrm{~mm} / \mathrm{yr}$ without a marked dry season (driest month: March, average $152 \mathrm{~mm}$; wettest month: July, average $480 \mathrm{~mm}$ ). The average monthly temperature is $25.8^{\circ} \mathrm{C}$ (Sanford et al. 1994). The vegetation in the vicinity of the sampling sites consists of primary rain forests including forested swamps, open swamps, secondary forests, abandoned plantations, and managed habitats (Hartshorn and Hammel 1994) (Fig. 1). All the study sites were located within primary lowland tropical rain forest.

Sampling and Trap Design. Moths were collected at three trap sites and two tower sites (Fig. 1). Figure $2 b$ shows the construction of the automatic funnel traps (ENTO-TECH, B. Skule, Denmark). The 8-W UVA fluorescent light tubes (Sylvania, F8W/T5/BL350) operated during the entire night from dusk $(\approx 1830$ hours) to dawn ( $\approx 0530$ hours) using photoswitches. 
In addition, light towers (Fritz Weber, Stuttgart, Germany) were installed at two sites close to trap sites 1 and 2 (Fig. 1). The towers consisted of a white gauze cylinder with two 15-W UVA tubes (Sylvania, blacklight blue, F15W/T8/BLB and Sylvania blacklight F15W/ BL350) located in their centers (Fig. 2a). All tubes emitted light at wavelenghts between 315 and $400 \mathrm{~nm}$ with peaks at 352 and $368 \mathrm{~nm}$ (product details by Sylvania). The tower's diameter was $\approx 0.70 \mathrm{~m}$ and its height $\approx 1.70 \mathrm{~m}$. Moths were sampled manually with jars from the gauze surface from 18.30 to $21.30 \mathrm{cov}-$ ering the peak activity of moths (Brehm et al. 2005). In both cases, KCN was used as a killing agent. Traps (tr) and towers (to) were operated from April to July in 2003 and from February to March in 2004 using 12-V lead batteries as power supply. All nightly samples of individual traps and towers were pooled (traps: $n=5$, 7, 8; towers: $n=8,8$ ). Appendix 1 provides a detailed list of all sampling dates. Towers were operated in the understory of the forest while traps were operated in both the understory (U) and in the canopy (C). Understory traps were installed on the ground at a height of 0.5-2 m. Canopy traps were either lifted upward on a rope to strong tree branches or installed on climate towers (Appendix 1). Understory and canopy traps were installed in close proximity but were not visible from each other.

Identification. The insects were identified by the first author at the Instituto Nacional de Biodiversidad (INBio) in Heredia, Costa Rica, the Natural History Museum in London (BMNH), the National Museum of Natural History in Washington, DC (USNM), the American Museum of Natural History in New York $(\mathrm{AMNH})$, and the Zoologische Staatssammlung München (ZSM). Identification was carried out by comparison with original type specimens or other reliably labeled material. Of the 358 separated morphospecies collected, 237 (66\%) were identified provisionally at species level by comparing external characters and, in doubtful cases, genitalia structures. In the Geometridae, nomenclature follows Pitkin (2002) for the largest subfamily Ennominae and otherwise the catalog of Scoble (1999). The classification of the Arctiidae follows Jacobson and Weller (2002). In the Arctiinae (Arctiini, Pericopini, Phaegopterini), the nomenclature follows Watson and Goodger (1986). Where species names could not be checked using a species catalog (Arctiinae: Ctenuchini/ Euchromiini; Lithosiinae), information was extracted from a BMNH online database (http://internt.nhm. ac.uk/jdsml/perth/lepindex/index.dsml). A complete species/morphospecies-site matrix is provided in Appendix 2 (electronic copy only). Voucher specimens will be deposited at INBio.

Statistical Analyses. Observed species numbers are not a reliable measure in incompletely sampled animal communities (Gotelli and Colwell 2001). For this reason, the largely sample size-independent diversity measure Fisher's $\alpha$ of the log series was used (Brehm et al. 2003). Fisher's $\alpha$ was calculated using EstimateS 7.00 software with 50 randomizations (Colwell 2004). The fit of the log series distribution was tested using a program by Henderson and Seaby (2001). Most samples fitted the log series (exceptions: Arctiidae: site U2 and pooled understory samples; Geometridae: pooled tower samples and pooled tower and trap samples). A randomization test (Solow 1993) implemented in the program of Henderson and Seaby (2001) was used to test for significant differences in diversity values. The pooled samples (U1-U3, Cl-C3, To1-To2) were ordinated using nonmetric multidimensional scaling (NMDS). NMDS in combination with the NESS or CNESS index of (dis-) similarity was recommended as an appropriate technique with which to analyze the structure of species rich moth ensembles (Brehm and Fiedler 2004). The sample size parameter $m$ of the NESS index was set to its maximum, yielding low stress values in the ordinations $(<0.10)$. Ordinations based on the NESS index with $m$ set to one and on the Sørensen index are not shown as they provided very similar results.

Faunal composition (Brehm and Fiedler 2003) was compared between light towers and understory traps. Arctiidae were analyzed at the level of the subfamilies Lithosiinae and Arctiinae (including the tribes Arctiini, Ctenuchini/Euchromiini, Pericopini and Phaegopterini). Geometridae were analyzed at the level of five subfamilies.

Wing length was used as a measure of body size (Hawkins and DeVries 1996), and a comparison was made between light towers and traps operated in the understory. Wing measurements were restricted to males. Three approaches for body size analysis were applied. (1) Mean male wing lengths for each species were calculated using males analyzed in this study and also by using males collected in other localities within a radius of $\approx 10 \mathrm{~km}$ of the study area (i.e., Parque Nacional Braulio Carrillo). The mean wingspan of each species was counted once. (2) The same data were used as in (1), except that species were weighted according to their abundance. (3) An analysis was carried out of the original measurements from males exclusively sampled in this study. Measurements were part of a larger study, and, because of time limitations, they were not performed for every male. Instead, wing length was measured for each male in species with no more than three males. In more common species, measurements were restricted to at least three males and $50 \%$ of all males in each species (example: when 50 males occurred, at least 25 were measured). The advantage of (1) and (2) was that wing length data of more species was available, whereas the advantage of (3) was the directness of the approach. Wing length differences were tested using a two-sided Kolmogorov-Smirnov (KS) test available in the internet (http://www.physics.csbsju. edu/stats/KS-test.html). Standard statistical analyses were carried out with the Statistica 5.5 software (StatSoft, Tulsa, OK).

\section{Results}

Kolmogorov-Smirnov tests did not reveal any significant differences between the average number of 
Table 1. Observed abundance, species richness, and Fisher's $\alpha$ of Arctiidae and Geometridae from understory (U) and canopy (C) trap samples and light tower samples of a lowland rain forest in Costa Rica

\begin{tabular}{|c|c|c|c|c|c|c|c|}
\hline & \multirow{2}{*}{$\begin{array}{c}\text { Sites } \\
\text { (nights) }\end{array}$} & Individuals & Observed species & $\alpha \pm \mathrm{SD}$ & Individuals & Observed species & $\alpha \pm \mathrm{SD}$ \\
\hline & & \multicolumn{3}{|c|}{ Arctiidae } & \multicolumn{3}{|c|}{ Geometridae } \\
\hline Trap U1 & $1(8)$ & 147 & 46 & $23.0 \pm 3.0$ & 218 & 67 & $33.0 \pm 3.5$ \\
\hline Trap U2 & $1(7)$ & 117 & 31 & $13.8 \pm 2.0$ & 76 & 43 & $41.0 \pm 8.4$ \\
\hline Trap U3 & $1(5)$ & 62 & 22 & $12.2 \pm 2.5$ & 79 & 43 & $38.6 \pm 7.6$ \\
\hline Trap Cl & $1(8)$ & 262 & 77 & $36.7 \pm 3.6$ & 405 & 64 & $21.4 \pm 1.8$ \\
\hline Trap C2 & $1(7)$ & 81 & 39 & $29.6 \pm 5.5$ & 78 & 30 & $17.9 \pm 3.3$ \\
\hline Trap C3 & $1(5)$ & 177 & 68 & $40.4 \pm 4.9$ & 90 & 40 & $27.6 \pm 4.8$ \\
\hline Tower 1 & $1(8)$ & 201 & 36 & $12.8 \pm 1.5$ & 424 & 89 & $33.8 \pm 2.7$ \\
\hline Tower 2 & $1(8)$ & 191 & 43 & $17.3 \pm 2.0$ & 400 & 90 & $36.1 \pm 2.9$ \\
\hline \multicolumn{8}{|l|}{ Combined data } \\
\hline $\mathrm{U}$ traps & $3(20)$ & 326 & 65 & $24.4 \pm 2.2$ & 373 & 99 & $44.0 \pm 3.6$ \\
\hline $\mathrm{C}$ traps & $3(20)$ & 520 & 120 & $48.9 \pm 3.4$ & 573 & 84 & $27.1 \pm 1.9$ \\
\hline Towers & $2(16)$ & 392 & 58 & $18.8 \pm 1.6$ & 824 & 130 & $42.9 \pm 2.5$ \\
\hline Towers $+\mathrm{U}$ traps & $5(36)$ & 718 & 95 & $29.3 \pm 1.0$ & 1196 & 168 & $53.2 \pm 2.6$ \\
\hline $\mathrm{U}+\mathrm{C}$ traps & $6(40)$ & 846 & 148 & $51.9 \pm 3.0$ & 946 & 140 & $45.4 \pm 2.5$ \\
\hline All & $8(56)$ & 1238 & 162 & $49.8 \pm 2.5$ & 1769 & 196 & $56.4 \pm 2.4$ \\
\hline
\end{tabular}

individuals in the understory traps and light towers in Arctiidae, whereas canopy samples were significantly larger than tower samples $(P=0.023, \mathrm{D}=0.475)$. In Geometridae, tower samples were significantly larger than both understory and canopy trap samples $(P<$ $0.001, \mathrm{D}=0.65$ and 0.70 , respectively). Appendix 1 provides data on nightly samples and medians.

In the Arctiidae, pooled understory trap samples were more diverse than tower samples, but differences were not significant and were not found to occur consistently at single sites (Table 1). Canopy trap samples were significantly more diverse than both understory trap samples and tower samples (Solow's randomization test: both $P<0.001$ ). In Geometridae, understory traps and towers yielded similar diversity values in pooled samples as well as at single sites. The pooled canopy trap samples were significantly less diverse than both pooled tower and understory trap samples $(P=0.004$ and $P=0.002$, respectively). As expected, combined samples of all sites and methods yielded the highest (Geometridae) or almost the highest (Arctiidae) numbers of species and diversity values (Table 1).
The NMDS ordination (Fig. 3) shows that in both families, tower sites, understory traps, and canopy traps are separated in three clusters. The (most important) first dimension separates tower and understory trap samples from canopy trap samples while the second dimension splits tower from understory sites. Figure 4 shows that faunal composition with regard to subfamilies also differs slightly between tower and understory trap samples. Results were not significant at the level of species (Arctiidae: $\chi^{2}=8.2 ; \mathrm{df}=4$; Geometridae $\chi^{2}=2.0 ; \mathrm{df}=4$ ), but significant at $P<$ 0.001 at the level of individuals (Arctiidae: $\chi^{2}=14.5$; Geometridae $\chi^{2}=41.9$ ).

No significant differences in wing length were detectable using the approach at species level. However, the two other approaches with emphasis on the abundance of species yielded significant results. In Arctiidae, moths collected at the towers tended to be slightly larger. However, the difference was small, and the result was significantly supported by only the second methodological approach. On the contrary, geometrids collected at the towers were significantly smaller than those collected in the traps (Table 2).

Table 2. Mean male wing length of Arctiidae and Geometridae sampled at two light towers and at three traps (U traps) in the understory of a lowland rain forest in Costa Rica

\begin{tabular}{|c|c|c|c|c|c|}
\hline & Site & $\begin{array}{l}\text { Mean } \\
(\mathrm{mm})\end{array}$ & SD & $n$ & $\begin{array}{l}\text { Komogorov-Smirnov } \\
\text { tests (two-sided) }\end{array}$ \\
\hline \multicolumn{6}{|l|}{ Arctiidae } \\
\hline \multirow[t]{2}{*}{ (1) Species count } & Towers & 13.89 & 3.71 & 41 & NS \\
\hline & $\mathrm{U}$ traps & 14.58 & 4.60 & 53 & \\
\hline \multirow[t]{2}{*}{ (2) Individuals count } & Towers & 13.44 & 2.02 & 328 & $P<0.001$ \\
\hline & $\mathrm{U}$ traps & 13.05 & 3.04 & 299 & Tower $>\mathrm{U}$ trap \\
\hline \multirow[t]{2}{*}{ (3) Direct measures } & Towers & 13.29 & 2.36 & 253 & NS \\
\hline & $\mathrm{U}$ traps & 13.24 & 2.93 & 263 & \\
\hline \multicolumn{6}{|l|}{ Geometridae } \\
\hline \multirow{2}{*}{ (1) Species count } & Towers & 13.57 & 6.46 & 79 & NS \\
\hline & $\mathrm{U}$ traps & 13.48 & 5.51 & 84 & \\
\hline \multirow[t]{2}{*}{ (2) Individuals count } & Towers & 11.03 & 6.14 & 484 & $P<0.001$ \\
\hline & $\mathrm{U}$ traps & 14.14 & 5.47 & 272 & $\mathrm{U}$ trap $>$ tower \\
\hline \multirow[t]{2}{*}{ (3) Direct measures } & Towers & 11.63 & 6.26 & 359 & $P<0.001$ \\
\hline & $\mathrm{U}$ traps & 14.33 & 5.43 & 238 & $\mathrm{U}$ trap $>$ tower \\
\hline
\end{tabular}

NS, not significant. 


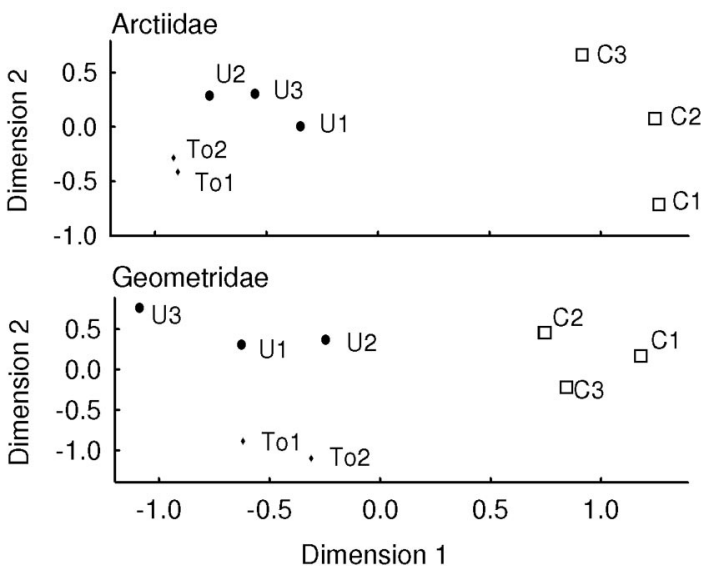

Fig. 3. Nonmetric two-dimensional scaling of ensembles of Arctiidae and Geometridae sampled in a rain forest in Costa Rica using either light towers (To) or automatic traps (understory, U; canopy, C). The NESS index of similarity $\left(m_{\max }\right)$ was used (Arctiidae: $m_{\max }=31$, NMDS stress $=0.02$; Geometridae: $m_{\max }=38$, NMDS stress $\left.=0.08\right)$.

This result was clearly supported by both abundanceoriented approaches. Figure 5 shows wing length histograms, based on the specimen-weighted approach. The smallest geometrid moths were only infrequently sampled in the traps whereas the size class of $15-20$

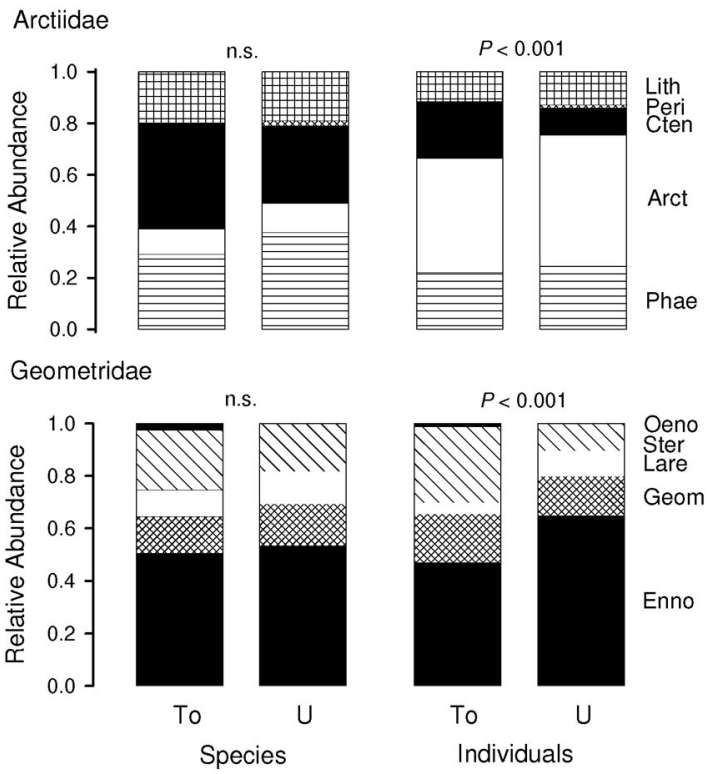

Fig. 4. Faunal composition of Arctiidae and Geometridae in samples from light towers (To) and automatic traps (U) operated in the understory of a rain forest in Costa Rica. Only differences based on the analysis of individuals (right) were significant, whereas differences in species composition (left) showed no significant differences ( $\chi^{2}$ statistics). Lith, Lithosiinae; Peri, Pericopini; Cten, Ctenuchini/Euchromiini; Arct, Arctiini; Phae, Phaegopterini; Oeno, Oenochrominae; Ster, Sterrhinae; Lare, Larentiinae; Geom, Geometrinae; Enno, Ennominae.

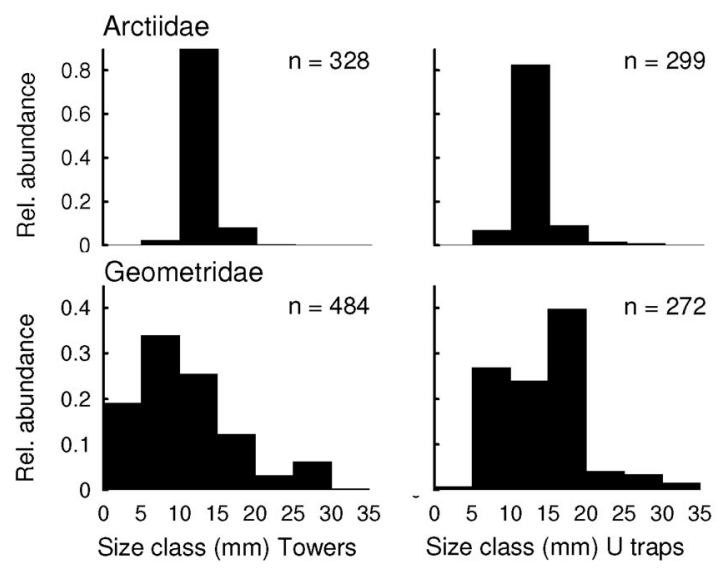

Fig. 5. Histograms showing the wing length of Arctiidae and Geometridae from pooled samples of light towers (Towers) and traps operated in the understory (U traps) of a lowland rain forest in Costa Rica. Mean wing lengths were calculated for males of each species and weighted for the presence of male individuals in each sample $(n)$. The graphs provide proportional data, given in intervals of $5 \mathrm{~mm}$.

mm was relatively strongly represented. Arctiids showed a very similar pattern in all samples with a strong emphasis on the wing length class of $10-15 \mathrm{~mm}$, mainly caused by the common genera Virbia and Melese.

\section{Discussion}

Abundance and Body Size in Understory Light Towers and Traps. Approximately four times more geometrid moth individuals were collected manually compared with traps (large variation: median tower samples $=45$, median trap samples $=12$ ). At first sight, this is not surprising because stronger light sources were used for manual sampling ( 2 by $15 \mathrm{~W}$ versus $8 \mathrm{~W})$. However, traps were operated during the whole night while manual sampling was restricted to a 3-h period after dusk. Axmacher and Fiedler (2004) found much more pronounced differences between the abundance of geometrid moths collected in traps and at light towers. Using very similar methods and sampling times as in this study in the montane rain forests at Mount Kilimanjaro (Tanzania), they collected $\sim 10$ times more geometrid moth individuals using light towers compared with traps, although the same 15-W UV fluorescent tubes were used in both devices. In the Arctiidae, no significant differences were detected, although there tended to be fewer specimens in the understory trap samples compared with tower samples $(P<0.10)$. As expected, sampling at towers was more effective with respect to sampled specimen per unit time. One reason for the lower numbers collected in the automatic traps could be the weaker UV tubes that were used (see above). However, the actual difference in light intensity was lower because the light of the tower tubes was partly reflected by the gauze and was possibly partly absorbed by a protective plas- 
tic cylinder $(\approx 10 \%)$ (F. Weber, personal communication). The difference between tower and trap samples can best be explained by a higher collecting efficiency at the towers. A trained collector can sample moths from the tower gauze surface immediately after they land. On the contrary, moths landing on the trap vanes do not necessarily fall into the funnel, and for this reason, some are able to escape (G. Brehm, unpublished data).

By interpretation of Geometridae subfamily ratios, Axmacher and Fiedler (2004) suggested that smallerbodied moths were disproportionally less collected with automatic traps. Body size data obtained in this study support this observation in Geometridae. Moths collected at light towers were significantly smaller than those collected in the traps, and it was shown that a significant shift in the subfamily composition occurred. A closer inspection of the data at species level reveals that very small Sterrhinae moths in particular were underrepresented in the trap samples (Appendix 2, electronic copy). For example, the three commonest Idaea species, I. speciosa (mean wing length $8.0 \mathrm{~mm})$, I. ustimargo $(4.4 \mathrm{~mm})$, and I. vagula $(4.5 \mathrm{~mm})$ were abundant in the pooled tower samples $(15,50$, and 72 specimens), whereas they were uncommon in the trap samples (understory: 8, 2, 0; canopy 7, 2, 2 specimens). Very small species were thus more likely to escape a trap than larger ones, possibly because of their very low body weight. Gravity probably has a stronger effect on heavier moths such as those in the wing length class of $15-20 \mathrm{~mm}$, which are more likely to drop down on flying into a trap vane. Arctiids showed no differences in wing size, possibly because they were generally larger than geometrid moths in the study area (median Geometridae: $12.0 \mathrm{~mm}$, median Arctiidae: $14.5 \mathrm{~mm}$; KS test, $P<0.001$ ). To fully understand the mechanisms responsible for the observed bias, the "small moths escape" hypothesis should be experimentally tested in the future by direct quantitative observations. Another problem associated with small species is that they are particularly sensitive to damage in traps, e.g., by large crawling beetles (Robinson and Tuck 1993). On the contrary, this problem does not apply to manual sampling.

Diversity and Sampling Method. In both families, no significant differences in moth diversity (Fisher $\alpha$ ) were found between the light tower and understory trap samples. Axmacher and Fiedler (2004) also reported similar values obtained from both techniques in mature forest habitats at Mount Kilimanjaro (but a higher diversity of tower samples in clearings and secondary forests). Hence, results from a combined measure of abundance and species richness such as Fisher's $\alpha$ yielded similar results. However, in both Arctiidae and Geometridae, observed species numbers differed considerably (Table 1). In terms of efficiency and the sampled number of species, light towers performed better in Geometridae, whereas this was not evident in the Arctiidae.

When combined samples for the different locations were compared (Table 1), both families reached diversity maxima (expressed as Fisher's $\alpha$ ) by a different combination of samples. In Geometridae, the combination of ground-based tower and trap samples led to a diversity maximum that was only slightly lower than in the combination of all samples. On the contrary, overall arctiid diversity is strongly underestimated if only understory samples are considered. Canopy traps yielded most species, and they were significantly more diverse than the other samples (ecological interpretations: Brehm 2006). Hence, additional canopy sampling is highly recommended to obtain a representative picture of arctiid moth diversity in neotropical lowland rain forests. Similarly, DeVries et al. (1999) and DeVries and Walla (2001) showed that neotropical forest butterflies needed to be sampled in both the understory and canopy because of a significant beta diversity across the vertical dimension. Little is known whether moth sampling in gaps and at rainforest edges could substitute canopy sampling of moths to a certain extent. A number of arctiid species collected exclusively in the canopy in this study were indeed also collected at a gap (white area d in Fig. 1) using strong 160-W UV mercury vapor lamps (G. Brehm, unpublished data). However, the best location to collect canopy insects seems to be the canopy itself. One of the easiest ways to obtain such samples is probably to lift up automatic traps as was done in this study. Beck et al. (2002) showed that hand sampling can also be carried out in tropical canopies by using the single rope technique, while cranes, canopy walkways, etc., offer access to this stratum.

In conclusion, the results do not support the idea that light towers generally perform better in moth sampling than automatic traps, as was suggested by Axmacher and Fiedler (2004). The results presented here provide evidence that towers and traps both have strengths and weaknesses. Their use should hence be weighted in relation to factors such as the moth taxon, the availability of manpower or ethical considerations (automatic traps often cause considerable "collateral damage" to other arthropods). Having been used in a number of quantitative studies in the last years, light towers have proved to be an appropriate method by which to collect geometrid moths (see Introduction). Nevertheless, additional sampling with automatic traps in the understory and canopy may certainly be useful because this may help to achieve a better assessment of the species that tend to fly late in the night or that mainly occur in the canopy. Differences between full-night samples and part-night samples have rarely been quantified (but see Beck and Linsenmair 2006 for Sphingidae data). Thomas and Thomas (1994) found similar values of Fisher's $\alpha$ of geometrid moths in a temperate forest, but recommended allnight sampling for complete species inventories. However, this study showed that the use of traps alone is less efficient and could be biased because very small species tend to be neglected.

In Arctiidae, samples of understory light towers only represented a part of the overall diversity. Because of this the additional or single use of automatic traps in both the understory and canopy is recom- 
mended because no biases with regard to body size have been recorded in this family. However, it is unclear whether canopy sampling would be required in every forested habitat because moth stratification might be much less pronounced in forests at higher elevations, at steeper slopes, or in temperate regions (Brehm 2006). For an improved understanding of moth diversity patterns, more comparative methodological studies are required to further explore different kinds of light sources. Although comparisons between different types of mercury vapor traps have been performed (e.g., Taylor and Brown 1972, Taylor and French 1974, Intachat and Woiwod 1999), comparative studies between mercury vapor trap samples and fluorescent light samples in various habitats and with various taxa are desirable for the future. Crosscalibration will also be required with the development of new methods such as light diode technology.

\section{Acknowledgments}

We thank two anonymous reviewers for constructive comments. The Organization for Tropical Studies and the ALAS project (Arthropods of La Selva, NSF Grant DEB-0072702) provided excellent working facilities at the La Selva Biological station. We particularly thank J. T. Longino, D. Wagner, D. Brenes, R. Vargas, M. Paniagua, and F. Cascante for kind help and advice and the use of ALAS light traps. The Instituto Nacional de Biodiversidad (INBio) and the Ministerio del Ambiente y Energia, Sistema Nacional de Areas de Conservacion, helped to obtain research permits. C. Cardelús and R. G. Vargas provided kind help in the installation of the canopy traps. J. Britton improved the text linguistically. D. Clark and S. F. Oberbauer allowed access to a temporary climate tower. Many colleagues helped the first author to access museum collections, who offers particular thanks to L. M. Pitkin, J. W. Brown, P. Gentili-Poole, and S. Rab-Green. C. Raabe and C. Knake assisted with spreading moths and data input. The Deutsche Forschungsgemeinschaft supported this study (Grant BR 2280/1-1).

\section{References Cited}

Axmacher, J. C., and K. Fiedler. 2004. Manual versus automatic moth sampling at equal light sources - a comparison of catches from Mt. Kilimanjaro. J. Lepid. Soc. 58: 196202.

Axmacher, J. C., G. Holtmann, L. Scheuermann, G. Brehm, K. Müller-Hohenstein, and K. Fiedler. 2004. Diversity of geometrid moths (Lepidoptera: Geometridae) along an Afrotropical elevational rainforest transect. Div. Distrib. 10: 293-302.

Beck, J., and K. E. Linsenmair. 2006. Feasibility of lighttrapping in community research on moths: attraction radius of light, completeness of samples, nightly flight times and seasonality for Southeast-Asian hawkmoths (Lepidoptera: Sphingidae). J. Res. Lepid. 39: 18-36.

Beck, J., C. H. Schulze, K. E. Linsenmair, and K. Fiedler. 2002. From forest to farmland: diversity of geometrid moths along two habitat gradients on Borneo. J. Trop. Ecol. 17: 33-51.

Bowden, J. 1982. An analysis of factors affecting catches of insects in light traps. Bull. Entomol. Res. 72: 535-556.

Brehm, G. 2006. Contrasting patterns of vertical stratification in two moth families in a Costa Rican lowland rain forest. Basic Appl. Ecol. doi: 10.1016/j.baae.2006.02.002.
Brehm, G., and K. Fiedler. 2003. Faunal composition of geometrid moths changes with altitude in an Andean montane rainforest. J. Biogeogr. 30: 431-440.

Brehm, G., and K. Fiedler. 2004. Ordinating tropical moth ensembles from an elevational gradient: a comparison of common methods. J. Trop. Ecol. 20: 165-172.

Brehm, G., D. Süssenbach, and K. Fiedler. 2003. Unique elevational diversity patterns of geometrid moths in an Andean montane rainforest. Ecography 26: 456-466.

Brehm, G., L. M. Pitkin, N. Hilt, and K. Fiedler. 2005. Montane Andean rain forests are a global diversity hotspot of geometrid moths. J. Biogeogr. 32: 1621-1627.

Canaday, C. L. 1987. Comparison of insect fauna captured in six different trap types in a douglas-fir forest. Can. Entomol. 119: 1101-1108.

Colwell, R. K. 2004. EstimateS: statistical estimation of species richness and shared species from samples, version 7.00. http:// purl.oclc.org/ estimates.

DeVries, P. D., T. R. Walla, and H. F. Greeney. 1999. Species diversity in spatial and temporal dimensions of fruitfeeding butterflies from two Ecuadorian rainforests. Biol. J. Linn. Soc. 68: 333-353.

DeVries, P. D., and T. R. Walla. 2001. Species diversity and community structure in neotropical fruit-feeding butterflies. Biol. J. Linn. Soc. 74: 1-15.

Gotelli, N., and R. K. Colwell. 2001. Quantifying biodiversity: procedures and pitfalls in the measurement and comparison of species richness. Ecol. Lett. 4: 379-391.

Hartshorn, G. S., and B. E. Hammel. 1994. Vegetation types and floristic patterns, pp. 73-89. In L. A. McDade, K. S. Bawa, H. A. Hespenheide, and G. S. Hartshorn (eds.), La Selva- ecology and natural history of a neotropical rain forest. The University of Chicago Press, Chicago, IL.

Hawkins, B. A., and P. J. DeVries. 1996. Altitudinal gradients in the body sizes of Costa Rican butterflies. Acta Oecol. 17: 185-194.

Henderson, P. A., and R.M.H. Seaby. 2001. Species diversity and richness. Pisces Conservation, Pennington, UK.

Hilt, N., and K. Fiedler. 2005. Diversity and composition of Arctiidae moth ensembles along a succession gradient in the Ecuadorian Andes. Div. Distrib. 11: 387-398.

Holloway, J. D., G. Kibby, and D. Peggie. 2001. The families of Malesian moths and butterflies. Brill, Leiden, The Netherlands.

Holyoak, M., V. Jarosik, and I. Novák. 1997. Weather-induced changes in moth activity bias measurement of long-term population dynamics from light trap samples. Entomol. Exp. Appl. 83: 329-335.

Intachat, J., and I. P. Woiwod. 1999. Trap design for monitoring moth biodiversity in tropical rainforests. Bull. Entomol. Res. 89: 153-163.

Jacobson, N. L., and S. J. Weller. 2002. A cladistic study of the Arctiidae (Lepidoptera) by using characters of immatures and adults. Thomas Say Publications in Entomology, Monographs, Lanham, MD.

Leinonen, R., G. Söderman, J. Itämies, S. Rytkönen, and I. Rutanen. 1998. Intercalibration of different lighttraps and bulbs used in moth monitoring in northern Europe. Entomol. Fenn. 9: 37-51.

McGeachie, W. J. 1989. The effects of moonlight illuminance, temperature and wind speed on light-trap catches of moths. Bull. Entomol. Res. 79: 185-192.

Muirhead-Thomson, C. R. 1991. Trap responses of flying insects. Academic, London, UK.

Pitkin, L. M. 2002. Neotropical ennomine moths: a review of the genera (Lepidoptera: Geometridae). Zool. J. Linn. Soc. 134: 121-401. 
Robinson, G. S., and K. R. Tuck. 1993. Diversity and faunistics of small moths (Microlepidoptera) in Bornean rainforest. Ecol. Entomol. 18: 385-393.

Sanford R. L., Jr., P. Paaby, J. C. Luvall, and E. Phillips. 1994. Climate, geomorphology, and aquatic systems, pp. 19-33. In L. A. McDade, K. S. Bawa, H. A. Hespenheide, and G. S. Hartshorn (eds.), La Selva-ecology and natural history of a neotropical rain forest. The University of Chicago Press, Chicago, IL.

Schulze, C. H., K. E. Linsenmair, and K. Fiedler. 2001. Understorey versus canopy: patterns of vertical stratification and diversity among Lepidoptera in a Bornean rain forest. Plant Ecol. 153: 133-152

Scoble, M. J. (ed.). 1999. Geometrid moths of the world: a catalogue (Lepidoptera: Geometridae). CSIRO, Collingwood, Australia.

Solow, A. R. 1993. A simple test for change in community structure. J. Anim. Ecol. 63: 191-193.
Taylor, L. R., and E. S. Brown. 1972. Effects of light-trap design and illumination on samples of moths in the Kenya highlands. Bull. Entomol. Res. 62: 91-112.

Taylor, L. R., and R. A. French. 1974. Effects of light-trap design and illumination on samples of moths in an English woodland. Bull. Entomol. Res. 63: 583-594.

Thomas, A. W., and G. M. Thomas. 1994. Sampling strategies for estimating moth species diversity using a light trap in a northeastern softwood forest. J. Lepidop. Soc. 48 85-105.

Watson, A., and D. T. Goodger. 1986. Catalogue of the neotropical tiger moths. Occ. Pap. Syst. Entomol. 1: 1-71.

Received for publication 12 June 2005; accepted 21 March 2006 